\title{
KSim: an Information System for knowledge management in Digital Factory
}

\author{
Bouzid M. ${ }^{1,2}$, Ayadi M. ${ }^{2}$, Mansour I. ${ }^{3}$, Cheutet V. ${ }^{4, *}$, Haddar M. ${ }^{2}$ \\ ${ }^{1}$ QUARTZ/SUPMECA, 3 rue Fernand Hainaut 93407 Saint-Ouen Cedex, France \\ \{marwa.bouzid, mohamed.ayadi\}@ supmeca.fr \\ ${ }^{2}$ LA2MP/ENIS, B.P 1173, w.3038 Sfax, Tunisie \\ mohamed.haddar@enis.rnu.tn \\ ${ }^{3}$ Univ Lyon, INSA Lyon, LIRIS UMR5205, 20 avenue A. Einstein 69621 Villeurbanne, France \\ ikbal.mansour@insa-lyon.fr \\ ${ }^{4}$ Univ Lyon, INSA Lyon, DISP Lab EA4570, 21 avenue J. Capelle 69621 Villeurbanne, France \\ vincent.cheutet@insa-lyon.fr \\ * Corresponding author
}

Abstract: The key of successful industry is to satisfy the customer requirements at the perfect delay with improved quality and cheaper price. In this context, Digital Factory $(D F)$ is known to test and validate the couple product-production system during the Product Development Process (PDP), with the usage of production system simulations. Therefore we can use an information system to integrate and manage all information related to product, process and simulation in this context. But with this huge amount of information, an actor of PDP may be confused about making a good decision at this particular stage. Thus, there is a lack of knowledge capitalization and sharing between PDP actors. On the basis of previous research works that contribute to the definition of a DF information system, we propose a new module, named KSim, dedicated to the capitalization and management of knowledge and experiences coming from previous projects in the DF context.

Keywords: Knowledgecapitalization, Knowledgemanagement, Digital Factory, information system, Product Development Process

\section{INTRODUCTION}

In recent decades, a large number of companies sought to value the intangible investment (research and development, training, advertising, organizational methods, etc.) and, in particular, their knowledge asset. This asset should be then re-used in different situations in order to reduce the costs and the time of development. In 1991, Tom Stewart advised the company to focus more on their knowledge than on their material goods: "Intellectual capital is becoming corporate America's most valuable asset and can be its sharpest competitive weapon. The challenge is to find what you have -and use it" (Stewart, 1991).

Among such knowledge-based situations, digital prototyping, based on the concepts of digital models representing the product, its physical behaviour, and its manufacturing process, is a solution to test and validate a product earlier in its lifecycle (Hoppmann, 2009). In particular, Digital Factory (DF) has emerged to design and simulate production systems throughout the product design process. It can be defined as a set of software tools and methodologies allowing the design, simulation, initiation and optimization of production systems (Kuehn, 2006; Chryssolouris, et al., 2009). With this definition it is clear that knowledge management is very important in DF. 
Indeed, the intrinsic complexity of DF due to the different co-existing levels of detail (from the operation on a specific station to the global supply chain) and to the variety of simulation types (prescriptive vs. based on events) implies different semantics for the actors then the complexity of communication between actors (Ayadi, et al., 2015). Moreover, proper simulation-based operations-level planning and control during project execution require that attributes of the corresponding simulation model elements are modified according to project progress. So, ultimately the simulation model can be completely adaptable and responsive to the latest site conditions. This underlines the importance of a robust methodology that supports the prospect of reliable collection and processing of field data and effective extraction of relevant contextual knowledge (Akhavian \& Behzadan, 2013). Digital manufacturing is defined as a key research area for the implementation of the knowledge-based factory of the future. It will be a key element in product and process knowledge acquisition, helping to translate from implicit to explicit knowledge (Chryssolouris, et al., 2009).

Despite the high performance of simulation tools in digital manufacturing, there is a lack of deployment related to the intrinsic complexity of DF, but above all to the absence of information and knowledge integration from previous projects of production systems simulation (Nagalingam \& Lin, 2008). The management of information and knowledge between the product and its production process, including data related to resources, is so essential. Indeed, the solution adopted for PDP is to integrate different types of information and knowledge (product, process and resources) as soon as possible to make the right decisions at the right time (Prasad, 1999). Based on previous research works, the Info Sim framework is already dedicated to DF data and information management and control (Ayadi, et al., 2015). Nevertheless, we identify the following research gap: how to manage and control all knowledge types in the context of DF, including product, process, resource and DF simulation ones?

The main objective of this research work is to model and implement, in a complementary way to Info Sim, a framework for the management and control of knowledge for DF. This framework allows to manage and improve the possible DF simulations, and also it focuses on knowledge capitalization and experience feedback towards new DF projects. Moreover, in the current situation of fast evolution of communication technologies and organisation strategies, the framework will be design to be as agile as possible.

This paper is structured as follows. Section 2 presents a study of the literature: first, we define knowledge entities then we analyse existing knowledge management systems. Section 3 describes the conceptual model of the proposed framework which will be validated with case studies presented in section 4. Section 5 presents the implementation of KSim and its validation on the study case. Finally, section 6 presents our conclusions and perspectives.

\section{STATE OF THE ART}

\subsection{Knowledge entities}

Knowledge can be defined as refined, synthesized, systematized information, or as information associated with a context of use (Baizet, 2004; Grundstein, et al., 2003). (Alavi \& Leidner, 2001) affirms that knowledge is information possessed in the mind of individuals: it is personalized information (which may or may not be new, unique, useful, or accurate) related to facts, procedures, concepts, interpretations, ideas, observations, and judgments. An information is converted to knowledge once it is processed in the mind of individuals and knowledge becomes information once it is articulated and presented in the form of text, graphics, words, or other symbolic forms. A significant implication of this view of knowledge is that for individuals to arrive at the same understanding of data or information, they must share a certain knowledge base. Said differently, a viewpoint is taken by an individual according to his/her knowledge, domain of competence and his/her objective in his/her activity (Ribière 
\& Matta, 1998). Moreover, these viewpoints correspond to the different ways to translate knowledge with respect to the social position, know-how and competence of an expert (Ribière \& Dieng, 1997).

Most of the authors divide knowledge into two kinds: explicit knowledge and tacit knowledge (knowhow) (Grundstein, et al., 2003; Nonaka \& Takeuchi, 1997). Explicit knowledge refers to knowledge transmitted through a "formal and systematic" language. It is a technical or academic data or information that is described in formal language, like manuals, mathematical expressions, copyright and patents. Tacit knowledge refers to know-how that is difficult to formalize and communicate and cannot be transferred that by the willingness of people to share their experiences. It is usually acquired over a long period of learning and experience (Grundstein, et al., 2003).

(Merrill, 1998) proposes a knowledge representation scheme consisting of knowledge components arranged into knowledge objects. The knowledge object is a precise way to describe the subject matter content or knowledge to be taught. It is a framework for identifying necessary knowledge components. It is a way to organize a data base (knowledge base) of content resources (text, audio, video, and graphics) so that a given instructional algorithm (predesigned instructional strategy) can be used to teach a variety of different contents. Knowledge objects should consist of components that are not specific to a particular subject matter domain. A knowledge object can have five major components:

- the entity, some device, person, creature, place, symbol, object, thing;

- parts of the entity;

- properties of the entity (properties are qualities or quantities associated with the entity);

- activities associated with the entity (activities are actions that can be performed by the learner on, with, to, the entity);

- Processes associated with the entity (processes are events triggered by an activity or another process that change the value of properties of the entity).

Knowledge may be individual, but the knowledge asset belongs to the company. In such context, a corporate memory is an explicit, disembodied, persistent representation of the knowledge and information in an organization (Van Heijst, et al., 1997). (Kuhn \& Abecker, 1998) defines: "A Corporate or Organizational Memory can be characterized as a comprehensive computer system which captures a company's accumulated know-how and other knowledge assets and makes them available to enhance the efficiency and effectiveness of knowledge-intensive work processes". The memory of an enterprise includes not only a "technical memory" obtained by capitalization of its employees' know-how but also an "organizational memory" (or "managerial memory") related to the past and present organizational structures of the enterprise (human resources, management, etc.) and "project memories" for capitalizing lessons and experience from given projects or for project definition, activities, history and results (Ribière \& Matta, 1998).

DF needs the integration of all knowledge (tacit and explicit) in the different layer (product, process, resource and simulation) to construct the corporate memory. So, in our research we will use the notion of viewpoint in the extraction of knowledge entities for all PDP actors (designer, manufacturer and simulator).

\subsection{Knowledge Management System}

(Barquin, 2001) defines "knowledge management is the process through which an enterprise uses its collective intelligence to accomplish its strategic objectives". We can summarize clearly the aim of the KM operation with: "Getting the right knowledge to the right people at the right time in the right size without being asked". (McMahon, et al., 2004) assumes that there are two approaches in KM: Codification (which focuses on the reification of knowledge so focuses only on explicit knowledge) (Prasad, 2001; Prasad \& Rogers, 2005) and personalization (which focuses on individuals as holders of knowledge and so tries to take into account tacit and explicit knowledge) (Beylier, et al., 2009). 
(Alavi \& Leidner, 2001) affirms that a system designed to support knowledge in organizations may not appear radically different from other forms of information systems, but will be geared toward enabling users to assign meaning to information and to capture some of their knowledge in information and/or data. And they defined the Knowledge management systems (KMS) that refers to a class of information systems applied on organizational knowledge management. These systems cannot be reduced solely to the Information Technology but it also corresponds to "sets of social actors" that storing and transforming the representations in a perspective of $\mathrm{KM}$ (creation, storage, transfer, integration and use of knowledge) mostly of the time via information technology (Gaumand, 2014).

In the literature, different approaches and tools dedicated to KM have been proposed in close contexts. As an example, (Chen, et al., 1998) proposes a systematic approach to develop a KM system in the context of virtual enterprise. Such approach is generic by nature and we partially based ourselves on it to perform the system development (mainly system analysis and system modelling).

(Yan, et al., 2001) develops a prototype tool that proactively supports designers in making aware of design decisions, through the timely revelation of knowledge about manufacturing and assembly processes. And (Baxter, et al., 2007) presents an approach for reusing engineering design knowledge. This approach supported three knowledge types: process knowledge, product knowledge, and task knowledge. (Zheng, et al., 2008) proposes a six-level systematic knowledge model to represent process knowledge with various levels of granularity. Then (Dai, et al., 2015) proposes a novel quantitative approach for reliability modelling and verification of manufacturing processes. Based to the role of Key Characteristics (KC), such as product $\mathrm{KCs}$, Material KCs, operation KCs and equipment $\mathrm{KCs}$, such approach presents the process knowledge network of manufacturing processes.

All these systems and approaches do not fully meet the company needs in the context of DF, since they miss either the multiplicity of viewpoints, multiple granularity, etc. In fact, until today there is no common platform for integrating, storing, sharing and reusing all knowledge along the product life cycle in DF. In particular, we decide to focus on a mixed approach between codification and socialisation. A light codification of a knowledge entity is necessary to be stored in an information system but the actor is really interpreting it before usage. Moreover we make the hypothesis to propose a framework that aims at enhancing communication and sharing between actors. Such choices can be explained by the very small numbers of routine simulation projects, in particular in DF. Finally, according to current usages in terms of ICT (Cloud, social networks, etc.), we decide to favour light structuration and ad-hoc community for knowledge community creation and management, and not systemic process structures with consistent knowledge blocks such as proposed by (Prasad, 2002). We make the hypothesis that this choice will allow to design a more agile framework able to follow fast evolutions.

\subsection{Info Sim specification}

With these definitions, we propose to extend Info Sim with KSim module, for adding a context to such information and convert it in project knowledge. This new module will be dedicated to manage knowledge in this context, with a specific focus on knowledge capture and structuration. We decide to separate the two modules in order to reduce the amount of information that can visualized by any user at each moment. In this framework, the user has to consciously ask for knowledge and so really understand what he finds and will use. Moreover, in the DF context where most of the simulation projects are innovative and so with few carry-over between simulations, we decide to have a mixed approach between codification and personalisation as a good compromise between knowledge usability and system agility.

Info Sim is an information system dedicated to manage simulation information in DFcontext (Ayadi, et al., 2015). Its objective is the integration of product, production processes and simulation information. In the conceptual model of Info Sim (figure 1), DF entity covers the main classes of the model: Product Component, Process Component, Resource and Simulation. This class can also be associated to a file, 
version and to an experience that can be shared for future projects. DF Project which is associated to a control Graph is an aggregation of one or numerous Product, Process, Resource and Simulation.

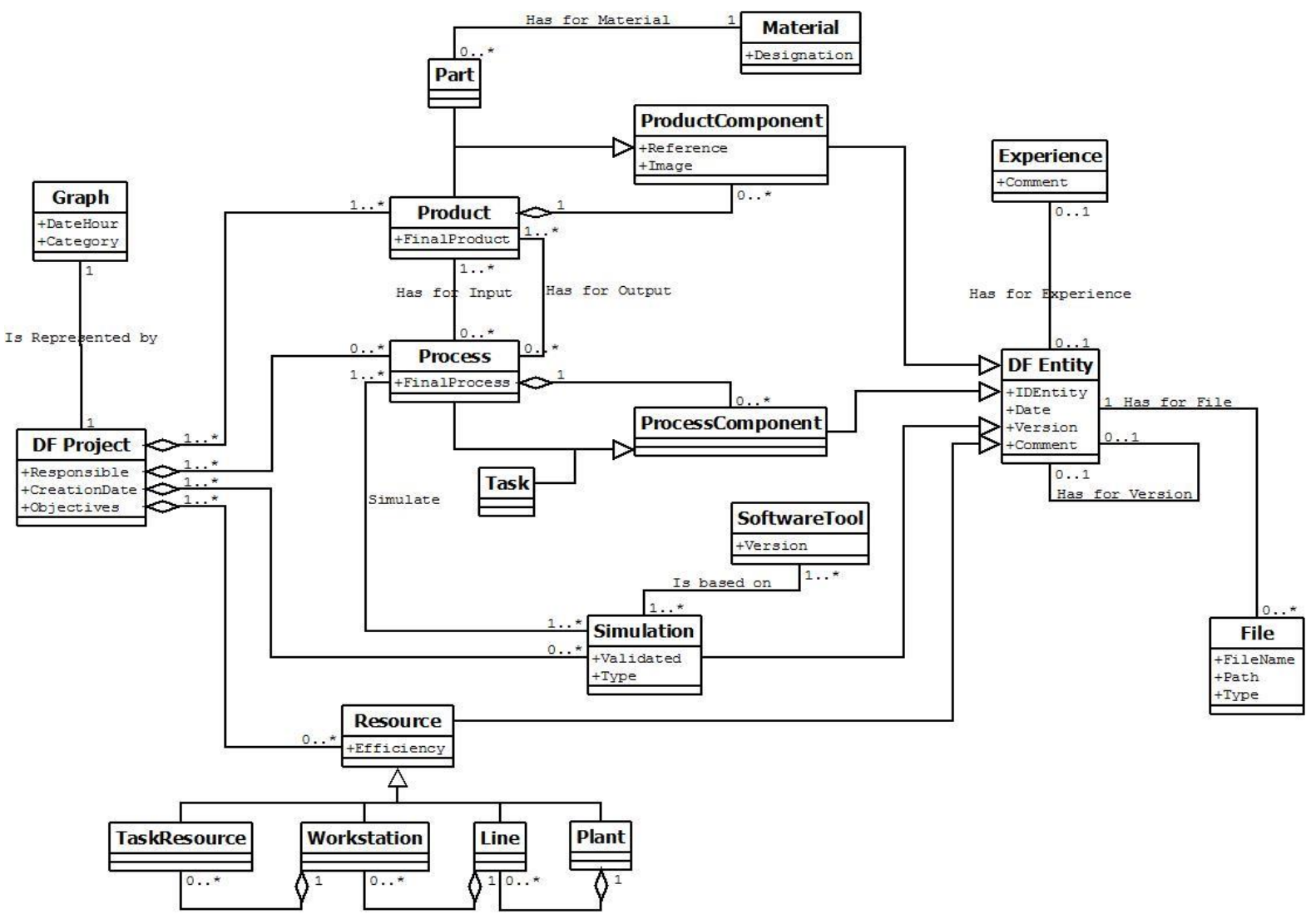

Figure 1: Conceptual model of Info Sim (Ayadi, et al., 2015).

\section{CONCEPTUAL MODEL}

In the proposed article, we choose a top down approach to model our proposition: we first propose a conceptual model (with the help of UML formalism), we after suggest the physical model on such bases. More formally, we first defined a use case diagram for our proposition (figure 4), in which we defined 3 main functions (Insert new General KnE, Create new Project KnE and Use KnE) that will be used by the same actors than the ones using Info Sim (DF project leader, designer, manufacturer and DF analyst). Thereafter, we defined the structure and the behaviour of the module, with the use of class diagrams (figures 2 and 3) and activity ones (figures 5 and 6). By nature, this conceptual model is linked to Info Sim one (depicted in figure 1) and so each diagram can be linked to the ones defined for Info Sim (Ayadi, et al., 2015). 


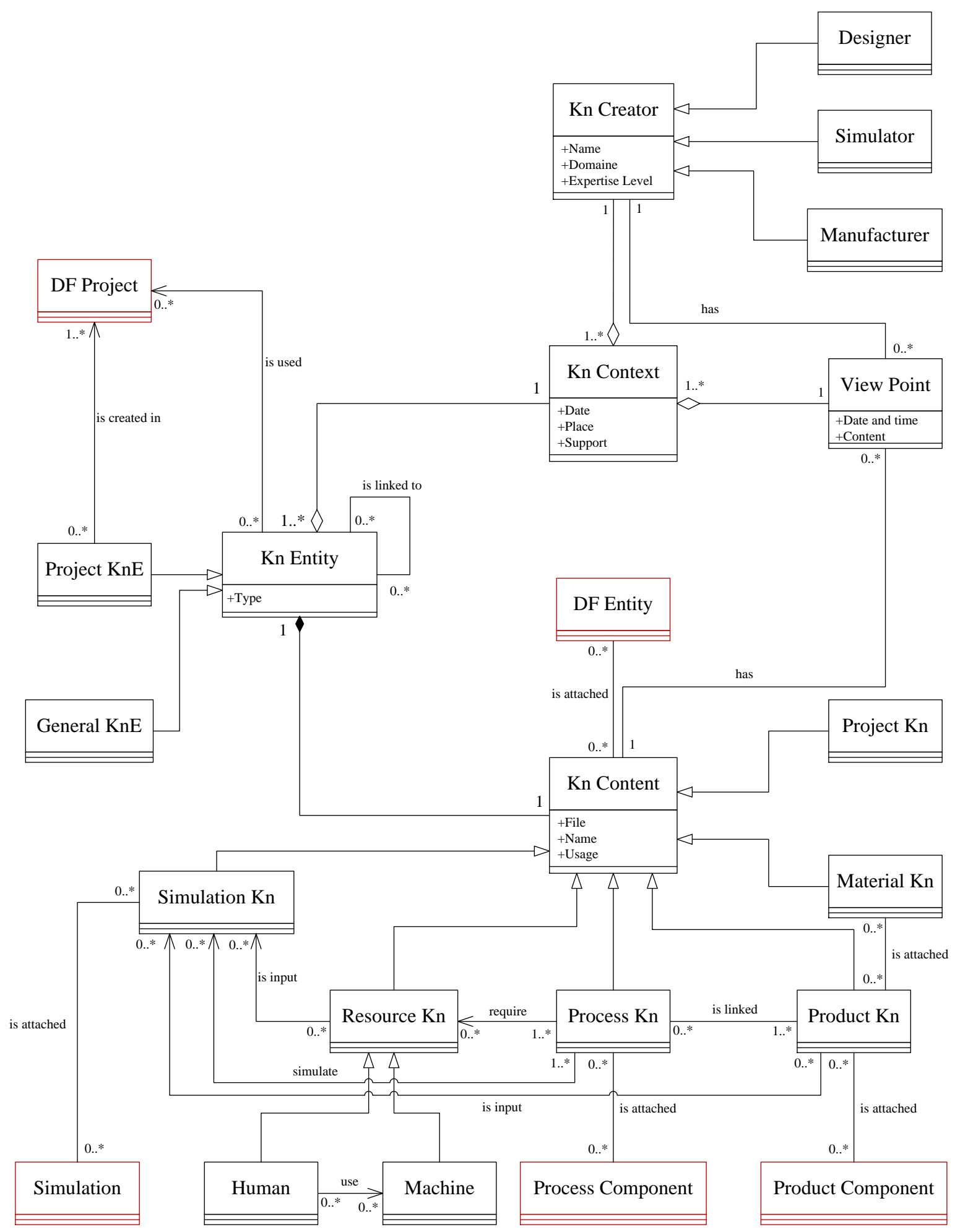

Figure 2: Conceptual Model of KSim 


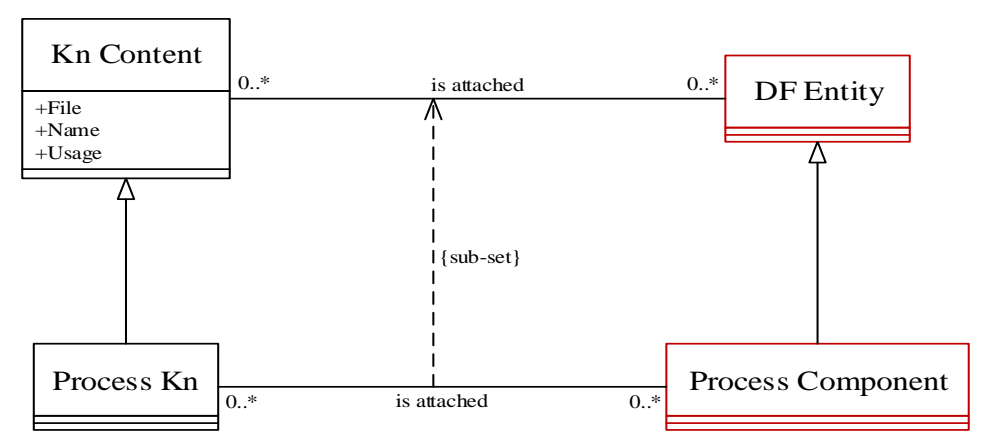

Figure 3: The link between information and knowledge project

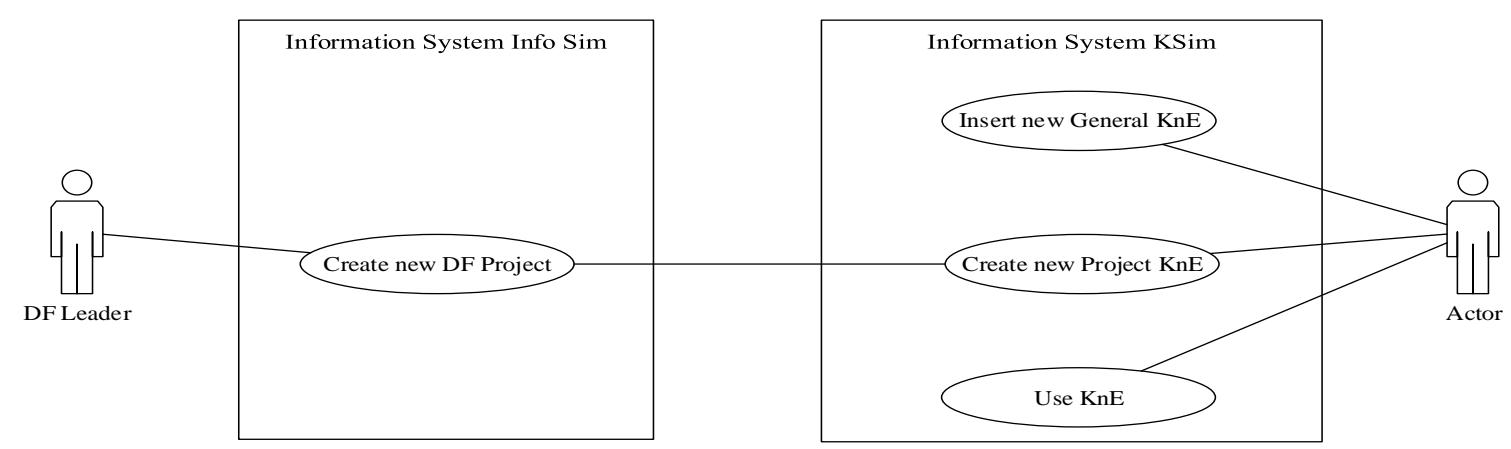

Figure 4: Use Case Diagram for knowledge in Digital Factor

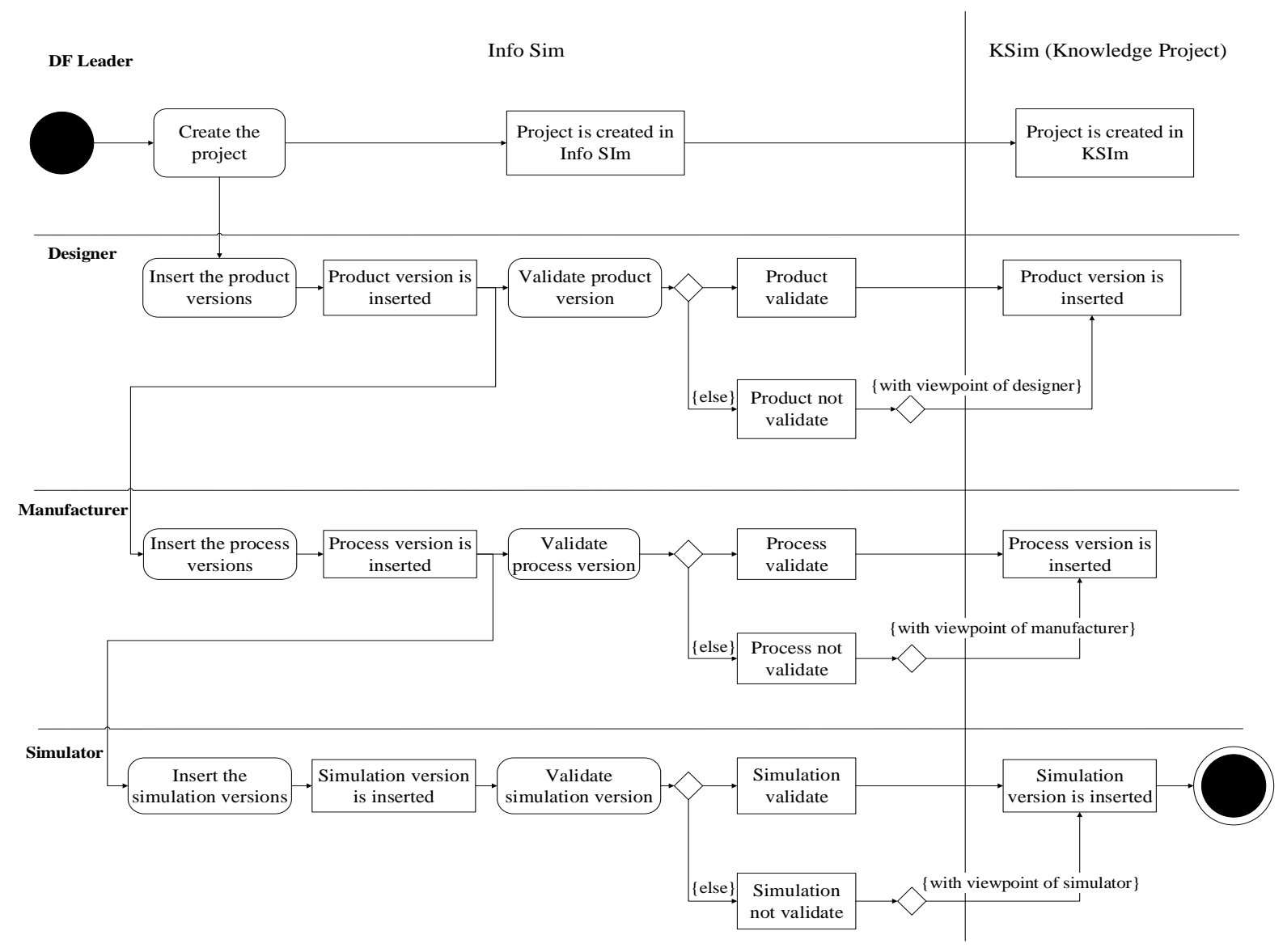

Figure 5: Knowledge project creation activity diagram 


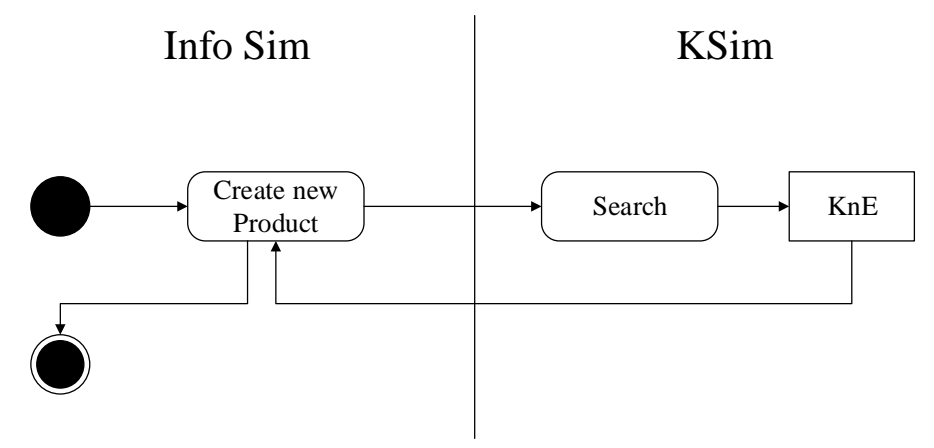

Figure 6: Knowledge entity use activity diagram

\subsection{Structural view of the conceptual model}

The class diagram of Kn_Entity is depicted in figure 2. In this model, the Kn_Entity class can be used in DF_project of Info Sim. This class includes the two main classes of the model: General_KnE and Project_KnE which is created attached to a specific DF_project of Info Sim. In the attribute of the super class, we can also specify the type of knowledge: tacit or explicit.

In (Davenport \& Prusak, 1998), the knowledge definition is "knowledge is a mix of framed experience, values, contextual information and expert insight that provides a framework for evaluating and incorporating new experiences and information". Based on this working definition, (Xu, et al., 2013) models the knowledge from the perspective of systems thinking with its content and its context. Then in our model, every knowledge element contains its own content ( Kn_Content class which gives a more detailed description of what is contained in the element) and is embedded in a specific context (Kn_Context class which depicts the comprehensive environment of the knowledge element for a better understanding).

We define a Kn_Context class as an aggregation of a Viewpoint and a Kn_Creator, associated to several local attributes (date, etc.). Kn_Context class is related to the $K n \_E n t i t y$ class by the aggregation relation, because each actor can create more knowledge and give its viewpoint in several knowledge.

In our modelling the Kn_Content class is linked with the Kn_Entity class through the composition relation, because if we remove the knowledge all its contents will be deleted. The Kn_Content (which contains the attributes like name, file, usage etc.) is attached to some DFEntity of Info Sim and so can be specialised accordingly: we so defined the classes Product_Kn,Process_Kn, Resource_Kn, Simulation_Kn,Material_Kn and Project_Kn. In fact, each information from Info Sim that it can be related to product component, process component or simulation can be knowledge if we validate this information or if we add a context to this information. The association link, named isAttached, between a Process_Kn class and a Process_Component one is modelled as a subset of the association link, also named is Attached, between Kn_Content class and DFEntity one. The idea is to constrain the relation to reduce the range of possible instances according to the initial set (figure 3).

Moreover, in the same way that the information between the DFEntity of Info Sim are linked, the $K n \_$Content can be linked together with specific semantics according to the type of Kn_Content. For instance, a Product_Kn can be an input for a Simulation_Kn.

\subsection{Behaviour view of the conceptual model}

In this section we develop a set of activity diagrams that represents the expected dynamics of the information system, based on the function defined in the use case diagram (figure 4). In figure 5 we describe the creation of knowledge project activity. In these activities four different actors are implied, the DF leader, the designer, the manufacturer and the simulator. Once the DF leader created the project in Info Sim, it will be created in KSim. In figure 5, the designer integrates all the products that are in the 
scope of the project with all versions in Info Sim (same things for manufacturer and simulator). After the automatic selection of the good information, we will find in KSim the validated version that we will use in this project and others versions (product version + the designer viewpoint) (process version + manufacturer viewpoint) (simulation result + simulator viewpoint) that we did not choose in this project but that can help us in another project. After, the designer (same thing for manufacturer and simulator) can see all viewpoints of each PDP actor, the errors and the results of previous projects, and can use it in the new project without losing time to redo all. Moreover, he/she can find all general knowledge in KSim which it canhelp him to obtain the right results and to make the right decision on this new project.

Figure 6 illustrates the use of knowledge entities in a new project. In this figure, the designer (or any other DF actor) can see all viewpoints of each PDP actor, the errors and the results of previous projects, and can use it in the new project without losing time to redo all. Moreover, he/she can find all general knowledge in KSim which can help him to obtain the right results and to make the right decision on this new project.

\section{CASE STUDY PRESENTATION}

In order to validate the proposed approach and the IS implementation, we based ourselves on three DF projects achieved by SUPMECA Paris students in collaboration with Airbus Group Innovation Works, from 2008 to 2010. Even if these projects are rather old, our industrial state-of-the-art highlights the progress made in terms of simulation information management, but the knowledge asset remains under-analysed and controlled in such context. For these projects, we have access to the different choices and associated rationales of the students. We so replayed these three projects with different participants that tried to be as closed as possible to the previous runs.

All these three projects aimed at designing, simulating and improving aeronautic assembly lines, using DF tools and methodologies. They were conducted by master students (on average 12 students during 4 weeks per year), with direct collaboration with the industrial partner. During the projects, each student took a particular role in the project.

The first two years, the project objective was to design, simulate and improve the final assembly line of an aircraft at a strategic level only, with several scenarios tested and explored (figures 7.a and 7.b). The last year, the project objective was to design, simulate and improve the assembly line of a specific aircarft section at strategic and tactic levels, with several scenarios tested and explored, and new constraints/objectives added (increase of production rate, investment minimization during time, etc.) (figure 7.c). On this particular projet, more than 15 simulations and 300 files have been generated.

All the data, information, knowledge and experiences generated during these projects are implemented in Info Sim and KSim in the same chronological order that they were used or generated during the projects. These projects already allowed us to validate that Info Sim is able to integrate different information of product, manufacturing process and simulation in DF (Ayadi, et al., 2015). The objective here is now to validate that KSim, in relation with Info Sim, is able to integrate and share knowledge objects in the considered context. 

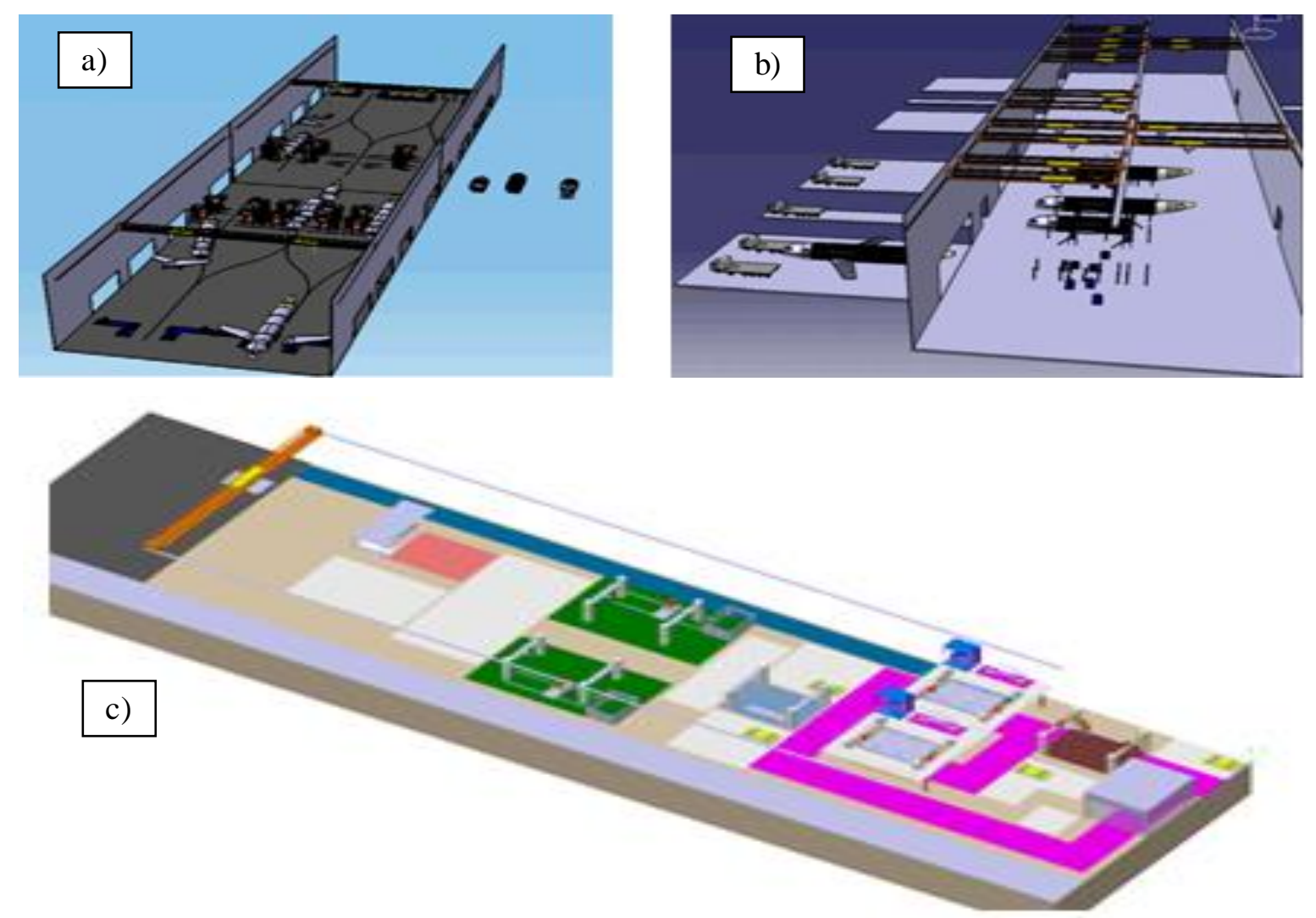

Figure 7: Case study presentation: a) first alternative of FAL from 2008 project, b) updated FAL from 2009 project, c) assembly line from 2010 project

In such projects, knowledge capitalisation, sharing and use have been not only intra-project, but also inter-projects and with all lectures the students followed. In the considered projects, the general knowledge objects came from two main sources:

- Lectures provided during their scholarship: tutorial on DF software tools, operation management, facility sizing, project management, etc.

- The industrial partner: classical aeronautic routings, safety rules, resources, etc.

These objects were possibly already available to the students, or were asked by them and capitalised in the project environment. In particular several tacit knowledge objects have been identified during the project (stations stopped when a crane go over, etc.).

Two cases appeared for the project knowledge objects. A lot of them were generated and directly used in the same project, like workstation capacity, specific assembly constraints, etc. For some of them, students were interested and used some project knowledge objects coming from previous projects. The discussion in this case can be if these objects can be "promoted" to be general ones.

\section{IMPLEMENTATION AND VALIDATION}

\subsection{Implementation}

We choose Windev of PCSoft for representing a data physical model of Info Sim and KSim. The aim of this work will be to enable the model to support the integration and reuse all DFknowledge. Thus we will implement and test our model in the information system Info Sim. 
For example, firstly, we will create a project in Info Sim then it will be created automatically in the project knowledge of KSim. After, we will integrate the parts with their materials and process of assembly and manufacturing. So we need to know the availability of material, standard parts, tools, machines in the company with their characteristics then we will use the general knowledge of KSim (figure 8.a). Finally, from this information we will find the better versions of parts, process, simulation and the viewpoints of PDP actors are automatically stored in project knowledge of KSim.

For another example, we will do another project similar to the previous project with a small difference in the dimensions or a change in the resource. Then in this case, we will use all results of previous project (calculation, design, process and simulation), and we will just change the size or resource, with the consideration of all comments and we will get new results in a reduced time and fewer errors. So, we have validated the importance of project knowledge in the company (figure 8.b).

Figure 8.c shows the connections of all parts i.e. all relations of all parts. For example we find that the part B1 is in AB 11 assembly, and it is used in the B1 manufacturing and numerical B1 simulation. This table (figure 8.c) helps us to make the necessary changes, i.e. if we modify a part we find its all connected files and after we can modify them.

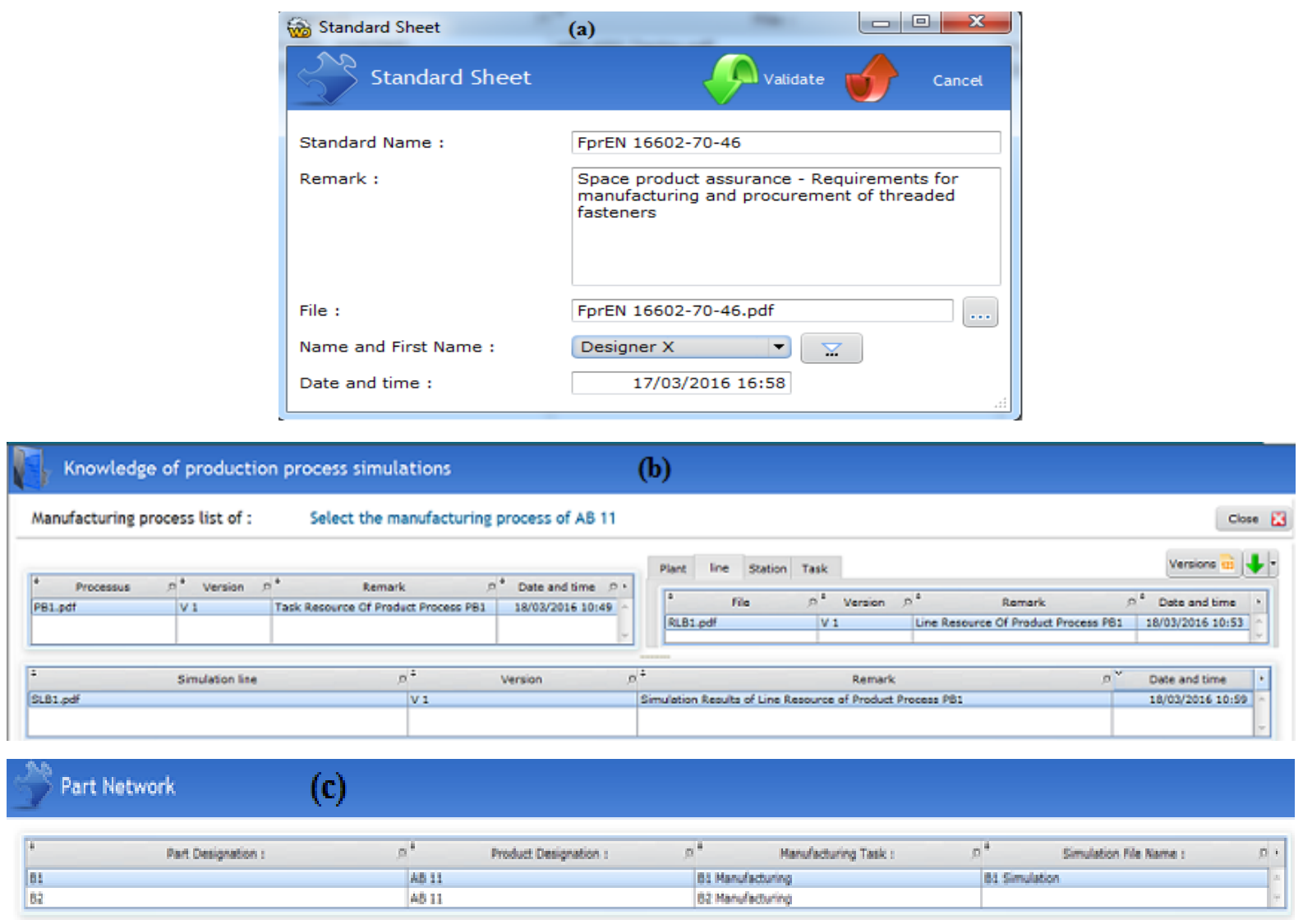

Figure 8: Screenshots of knowledge in KSim

\subsection{Results \& Discussion}

The aim of our research work is to choose the good information that is integrated in Info Sim, then to collect and store them in KSim. We validated it in the front part. In fact, our system will choose the best version which is used in this project and put it in KSim as project knowledge with other versions that we did not choose in this project but that can help us in another project. In this case our system will collect all comments, observations, remarks, viewpoints of all PDP actors and store them in project knowledge of KSim which can be knowledge related to product, process, resource and simulation. 
Furthermore, KSim system will also manage the general knowledge of the company as the material characteristic that are available in the company, technical data of equipment, standard parts, simulation results of previous projects, videos describing the operation of the machines. These are general knowledge that we will integrate them in KSim and we will use in the future projects of Info Sim, and helped us to choose the right solution as soon as possible.

Thus, we can conclude that we will develop an information system including Info Sim that manages all project information and KSim which is dedicated to the management of the projects and general knowledge and which is linked to Info Sim. Tables 1 and 2 show all knowledge that our information system can manage. We can see in these tables the content of project knowledge and general knowledge which it can be the product, process, resource or simulation with the knowledge context which it can be the viewpoint of designer, manufacturer or simulator.

\begin{tabular}{|c|c|c|c|c|c|}
\hline \multicolumn{2}{|c|}{ Kn Content } & Creator & $\begin{array}{c}\text { Designer } \\
\text { Viewpoint }\end{array}$ & $\begin{array}{l}\text { Manufacturer } \\
\text { Viewpoint }\end{array}$ & $\begin{array}{c}\text { Simulator } \\
\text { Viewpoint }\end{array}$ \\
\hline \multirow{6}{*}{ Product } & Material & $x$ & $x$ & $\times$ & $\times$ \\
\hline & Study and calculation & $x$ & $x$ & $x$ & \\
\hline & Part list & $x$ & $x$ & $x$ & $x$ \\
\hline & Part Simulation & $x$ & $x$ & $x$ & \\
\hline & Product list & $x$ & $x$ & $x$ & \\
\hline & Product simulation & $x$ & $x$ & $x$ & \\
\hline \multirow{2}{*}{ Process } & Part transformation process & $x$ & $x$ & $x$ & $x$ \\
\hline & Assembly Process & $x$ & $x$ & $x$ & $x$ \\
\hline \multirow{2}{*}{ Resource } & Worker list & $x$ & & $x$ & $x$ \\
\hline & Machine list & $x$ & & $x$ & $x$ \\
\hline Simulation & Simulation results & $x$ & $x$ & $x$ & $x$ \\
\hline \multicolumn{6}{|c|}{ Table 1. Project knowledge. } \\
\hline \multicolumn{2}{|c|}{ Kn Content } & Creator & Designer & Manufacturer & Simulator \\
\hline \multirow{6}{*}{ Product } & Material & $x$ & $x$ & $x$ & $\times$ \\
\hline & Standards & $x$ & $x$ & $x$ & $x$ \\
\hline & Standards Parts & $x$ & $x$ & $x$ & $x$ \\
\hline & Software tutorials & $x$ & $x$ & & \\
\hline & Designer Knowledge & $x$ & $x$ & & \\
\hline & Design rules & $x$ & $x$ & & \\
\hline \multirow{4}{*}{ Process } & Manufacturing videos & $x$ & $x$ & $x$ & $x$ \\
\hline & Manufacturer Knowledge & $x$ & & $x$ & \\
\hline & Software tutorials & $x$ & & $x$ & \\
\hline & Manufacturing rules & $x$ & & $x$ & \\
\hline \multirow{2}{*}{ Resource } & Worker list & $\bar{x}$ & $x$ & $x$ & $x$ \\
\hline & Machine list & $x$ & $x$ & $x$ & $x$ \\
\hline \multirow{4}{*}{ Simulation } & Simulation results & $x$ & $\bar{x}$ & $\bar{x}$ & $\bar{x}$ \\
\hline & Software tutorials & & & & $x$ \\
\hline & Simulator Knowledge & & & & $x$ \\
\hline & Simulation rules & & & & $x$ \\
\hline
\end{tabular}

Table 2. General knowledge.

It is important to note that Info Sim and KSim are not responsible for the generation of information and knowledge necessary to a good project proceeding, but it provides a better visibility of the project advancement and the access of different information and knowledge (in different format), which will help to take better decisions earliest during the PDP. So, we identify needs for consistent methods and 
tools for knowledge sharing and transfer inside KSim (Wang, et al., 2014). Moreover, KSim usage definition shares current trends of ICT (and particularly with social networks) for peer-to-peer elicitation of new knowledge.

The current prototype of the Info Sim and KSim framework has been presented to some industrial partners and received good feedbacks from them. A very first perspective of this work is the implementation of this model inside a company in order to identify scaling-up problems, especially in terms of knowledge entities networks and stakeholders with a particular focus on complexity.

\section{CONCLUSIONS AND PERSPECTIVES}

In this study, starting from the concept of knowledge Management, we propose a conceptual model that supports Knowledge integration in DF. Our model allows the creation, the sharing and the reuse of knowledge earliest during the PDP. It allows also the integration of all explicit and tacit knowledge of PDP actors and workers. In our model, we proposed that every company has two types of knowledge: project knowledge and general knowledge. Each of this knowledge has a context and content. Else we linked our model with the Info Sim model.

Indeed during the creation a new project we need to know all company knowledge (project and general knowledge) to make the right decision in the right time. Furthermore project knowledge is created by the DF project. Then, two industrial case studies have been presented for illustrating the applicability and validity of the proposed model. We described in these cases all the knowledge that we need during the process of design, manufacturing and simulation and all knowledge which it can be obtained during a project development.

Various prospects for future work have been proposed for this conceptual model. The aim of this work will be to enable the model to support the integration and reuse all knowledge in DF. But, the potential huge amount of knowledge that KSim can englobe requires adapted method for retrieving and sharing knowledge entities (Bouzid, et al, 2015), with specific methods for negotiation when conflicts between actors appear. Moreover we do not interest in the information and knowledge that circulate outside of the company such as information related to customer, suppliers, competitors... This type of information is very important for a PDP actor to make the right decision at the right time. Thus, there is a lack of exchange and sharing of information and knowledge between inside and outside of the company. Future works will focus on business intelligence and its relation with the knowledge management.

\section{REFERENCES}

Akhavian, R. \& Behzadan, A. H., 2013. Knowledge-based simulation modeling of construction fleet operations using multimodal-process data mining. Journal of Construction Engineering and Management, 139(11), p. 04013021.

Alavi, M. \& Leidner, D. E., 2001. Review: Knowledge management and knowledge management systems: Conceptual foundations and research issues. MIS quarterly, pp. 107-136.

Ayadi, M., Costa Affonso, R., Cheutet, V. \& Haddar, M., 2015. Info Sim: Prototyping an information system for Digital Factory management. Concurrent Engineering, 23(4), pp. 355-364.

Baizet, Y., 2004. Knowledge Management in design: Application to the computational mechanics at Renault-BED, University of Grenoble: $\mathrm{Ph}$. D Thesis.

Barquin, R. C., 2001. What is the knowledge management?. Knowledge And Innovation: Journal Of The KMCI, 1(2), p. 127-143.

Baxter, D. et al., 2007. An engineering design knowledge reuse methodology using process modelling. Research in engineering design, 18(1), pp. 37-48.

Beylier, C., Pourroy, F., Villeneuve, F. \& Mille, A., 2009. A collaboration-centred approach to manage engineering knowledge: a case study of an engineering SME. Journal of Engineering Design, 20(6), pp. 523-542. 
Bouzid, M., Ayadi, M., Cheutet, V. \& Haddar, M., 2015. Proposition of a conceptual model for knowledge integration and management in Digital Factory. Doha (Qatar), Proceedingss of PLM'15 conference.

Chen, Y. M., Liao, C. C. \& Prasad, B., 1998. A systematic approach of virtual enterprising through knowledge management techniques. Concurrent Engineering, 6(3), pp. 225-244.

Chryssolouris, G. et al., 2009. Digital manufacturing: history,perspectives, and outlook. Proceedings of the Institution of Mechanical Engineers, Part B: Journal of Engineering Manufacture, 223(5), pp. 451-462.

Dai, W., Maropoulos, P. G. \& Zhao, Y., 2015. Reliability modelling and verification of manufacturing processes based on process knowledge management. International Journal of Computer Integrated Manufacturing, 28(1), pp. 98-111.

Davenport, T. \& Prusak, L., 1998. Working Knowledge: How Organizations Manage What They Know. s.1.:Harvard Business Press.

Gaumand, C., 2014. Système de gestion des connaissances dédié à la chaîne logistique: une recherche intervention au sein de l'entreprise Bonfiglioli Transmissions, Ecole Centrale de Paris: $\mathrm{PhD}$ Thesis.

Grundstein, M., Rosenthal-Sabroux, C. \& Pachulski, A., 2003. Reinforcing decision aid by capitalizing on company's knowledge: Future prospect. European Journal of Operational Research, 145(2), p. $256-272$.

Hoppmann, J., 2009. The Lean Innovation Roadmap-A Systematic Approach to Introducing Lean in Product Development Processes and Establishing a Learning Organization-, Technical University of Braunschweig: $\mathrm{PhD}$ Thesis.

Kuehn, W., 2006. Digital Factory - Integration of simulation enhancing the product and production process towards operative control and optimisation. International Journal of Simulation, 7(7), p. 27 39.

Kuhn, O. \& Abecker, A., 1998. Corporate Memories for Knowledge Management in Industrial Practice: Prospects and Challenges. In : Information technology for knowledge management, pp. 183-206.

McMahon, C., Lowe, A. \& Culley, S., 2004. Knowledge management in engineering design: personalization and codification. Journal of Engineering Design, 15(14), pp. 307-325.

Merrill, M. D., 1998. Knowledge objects. CBT solutions 2, Volume 2, pp. 1-11.

Nagalingam, S. \& Lin, G., 2008. CIM-still the solution for manufacturing industry. Robotics and Computer-Integrated Manufacturing, 24(3), p. 332-344.

Nonaka, I. \& Takeuchi, H., 1997. The Knowledge-Creating Company. The economic impact of knowledge, p. 183.

Prasad, B., 1999. System integration techniques of sharing and collaboration among work-groups, computers and processes. Journal of systems integration, 9(2), pp. 115-139.

Prasad, B., 2001. Languages for knowledge capture and their use in creation of smart models. Dans: Springer, éd. Industrial Knowledge Management. London: s.n., pp. 525-547.

Prasad, B., 2002. Building blocks for a decision-based integrated product development and system realization process. Systems engineering, 5(2), pp. 123-144.

Prasad,B.\& Rogers, J., 2005. A knowledge-based system engineering process for obtaining engineering design solutions. ASME IDETC-CIE 2005.

Ribière, M. \& Dieng, R., 1997. Introduction of Viewpoints in Conceptual Graph Formalism. In Conceptual Structures: Fulfilling Peirce's Dream, pp. 168-182.

Ribière, M. \& Matta, N., 1998. Virtual Enterprise and Corporate Memory. Brighton (UK), Proceedings of the 1st Workshop OM-98, pp. 129-147.

Stewart, T. A., 1991. Brain Power. How Intellectual Capital Is Becoming America's Most Valuable. Fortune, 3 June.

Van Heijst, G., Van Der Spek, R. \& Kruizinga, E., 1997. Corporate Memories as a Tool for Knowledge Management. Expert Systems With Applications, 13(1), pp. 41-54. 
Wang, S., Noe, R. \& Wang, Z., 2014. Motivating knowledge sharing in knowledge management systems a quasi-field experiment. Journal of Management, 40(14), pp. 978-1009.

Xu, J., Houssin, R., Bernard, A. \& Caillaud, E., 2013. Systemic modeling of knowledge for innovation in design. CIRP Journal of Manufacturing Science and Technology, 6(1), pp. 1-12.

Yan, X. T., Borg, J. C. \& Juster, N. P., 2001. Concurrent modelling of components and realization systems to support proactive design for manufacture / assembly. Proceedings of the Institution of Mechanical Engineers, Part B: Journal of Engineering Manufacture, 215(8), pp. 1135-1141.

Zheng, L. Y. et al., 2008. Systematic modeling and reusing of process knowledge for rapid process configuration. Robotics and Computer-Integrated Manufacturing, 24(2), pp. 763-772. 